\title{
Who suffers from unemployment? The role of health and skills
}

\author{
Anton Nilsson
}

\section{Correspondence:}

Anton.Nilsson@nek.lu.se

Department of Economics and

Centre for Economic Demography,

Lund University, 22007 Lund,

Sweden

\section{Springer}

\begin{abstract}
Unemployment swings have distributional consequences if some groups are hit harder than others. We examine if the sensitivity to local unemployment rates varies by characteristics such as health, cognitive ability and non-cognitive ability. Data on these variables come from registers covering the entire Swedish population of males. We show that variations in the unemployment rate are associated with larger variations for those with poor health or with a low non-cognitive ability. This pattern is found both among young and older individuals. The employment of the lower-educated also varies more with variations in the unemployment rate, but only among younger workers.

JEL codes: 110; J24; J31; E32.

Keywords: Health; Cognitive ability; Non-cognitive ability; Education; Employment; Unemployment; Business fluctuations
\end{abstract}

\section{Introduction}

Economists have long been interested in what factors determine an individual's success in the labor market, such as the ability to find a job. Whereas older research has often focused on education, recent literature has shown the importance of health, cognitive ability and non-cognitive abilities (e.g., Heckman et al. 2006; Currie et al. 2010; Lindqvist and Vestman 2011; Lundborg et al. 2014a). In this paper, we examine if those with poor health and abilities face a "double penalty" in the sense that they are not only less likely to be employed in general, but their probability of employment is also more sensitive to the unemployment rate. In the presence of such a phenomenon, career and life planning becomes more difficult for disadvantaged individuals and they incur utility losses given that they are risk averse. ${ }^{1}$ Down the road, individuals with a heavily fluctuating employment status may lose human capital and suffer long-term consequences. Policy-makers may want to compensate or invest in individuals that are more sensitive to unemployment, or alternatively, reduce aggregate fluctuations by stabilization policies.

Going back to Tobin (1972), a number of authors have noted that unemployment has distributional consequences along some dimensions. An increase in unemployment is obviously associated with fewer hirings and/or more layoffs, but there is also evidence of a second-order effect; some groups of individuals are hit more by unemployment than others. So far, research has documented the differential effects of the unemployment rate by characteristics such as age, race, sex and education. While other characteristics such as cognition and social skills may be equally or even more important for labor market success, data

(c) 2015 Nilsson. Open Access This article is distributed under the terms of the Creative Commons Attribution 4.0 International License (http://creativecommons.org/licenses/by/4.0/), which permits unrestricted use, distribution, and reproduction in any medium, provided you give appropriate credit to the original author(s) and the source, provide a link to the Creative Commons license, and indicate if changes were made. 
on these are rarely available and studies have not considered unemployment sensitivity with respect to these.

In particular, previous studies have documented that low-educated individuals are more sensitive to the unemployment rate than higher educated individuals. The mechanisms behind this are not entirely clear. It is possible that the effects partly arise because of underlying differences in abilities correlated with education. This would seem reasonable as more able individuals often undertake more education than less able ones. It is also possible that results reflect the sorting of individuals into jobs with different characteristics. Our study is able to address these issues.

Our study uses a dataset from Sweden with several advantages. First, it includes highquality data on predetermined individual characteristics of virtually the entire population (of males). It is an important feature of these data that both health and skills are measured before labor market entry because it means that reverse causality is not an issue. Second, the data have been linked to tax records to determine whether or not individuals are employed (at some point) during a certain year. Third, we have data on regional unemployment for several years and we can control for both region- and year-specific effects that may be correlated with the unemployment rate. Fourth, we are able to identify individuals that move in order to examine if the results may be driven by mobility patterns.

Sweden has much stronger employment protection legislation than countries such as the U.S. and the U.K. (e.g., Nicoletti, et al. 1999), and we would therefore expect the sensitivity of groups that are disadvantaged, in terms of health or skills, to be smaller in our context. After working for the same employer for more than 2 years, the employee typically has the right to be offered a permanent contract. This means that middle-aged and older workers tend to have a stronger employment protection than the young, and we may expect effects to be concentrated in the group of young workers.

Our findings consistently suggest that individuals in poor health or with low noncognitive skills exhibit greater variations in their employment probability as the unemployment rate varies. The penalty is non-linear in the sense that the effects are much larger for individuals in poor health or with lower skills than for individuals with intermediate health and skills. Running our regressions for different age groups separately, we show that our results are not only driven by the group of younger workers. In other words, the effects do not only operate at labor market entry.

The rest of the paper is organized as follows. Section 2 provides a background discussion and an overview of the relevant literature. Section 3 describes the data and Section 4 lays out the empirical model. In Section 5, we present the results, and Section 6 concludes.

\section{Background}

Our work relates to three different branches of the literature. First, there is a growing amount of literature showing the importance of various dimensions of skills for labor market success. As surveyed by Card (1999), many decades of research have documented a positive association between educational attainment and outcomes such as wages and employment. More recently, much evidence has accumulated to suggest that cognitive and non-cognitive abilities (e.g., Heckman et al. 2006; Cebi 2007; Heineck and Anger 2010) and health (e.g., Smith 1999; Almond and Currie 2011) may be at least as important in determining an individual's success in the labor market. Lindqvist and Vestman (2011) used data on cognitive and non-cognitive abilities from the Swedish military enlistment records. 
When compared to cognitive ability, non-cognitive ability at the age of 18 was found to have much stronger effects on subsequent labor force participation and earnings at the lower end of the distribution. Using the same data source, Lundborg et al. (2014a) showed that many different health problems, as well as overall health, as determined at military enlistment had strong impacts on labor market outcomes such as earnings in middle adulthood. These effects were only partly explained by differences in cognitive and non-cognitive ability.

There is evidence that the labor market outcomes following the onset of sickness or disability vary by individual characteristics such as socioeconomics. Charles (2003) showed that earnings losses due to (self-reported) disability were larger among older, non-white and less educated workers and that for these groups earnings recovery was weaker as well. Using hospital data from Sweden, Lundborg et al. (2011) also documented that earnings losses due to health shocks were more pronounced among the low-educated, that among young workers these differences between the low- and the high-educated decreased over time, and that among older workers these differences instead increased over time. In sum, poor health appears to interact with socioeconomics, age and other characteristics in such a way as to produce adverse outcomes especially among the disadvantaged.

Second, studies have documented the effects of business cycles or unemployment on a range of outcomes. Some of these have asked if events such as recessions or job displacements affect health outcomes (Ruhm 2000; Sullivan and von Wachter 2009; Stillman and Thomas 2008; Currie and Tekin 2011). Other studies, such as Kletzer (1998) and Carneiro and Portugal (2006), have considered the long-run earnings effects of job displacements. Studies including Heckman and Borjas (1980), Raaum and Røed (2006); Eriksson and Rooth (2014) have tried to get at the question of whether past unemployment affects the probability of being hired, so called scarring effects. On the whole, this branch of literature has suggested that unemployment can have quite significant effects on individual outcomes in both the short and long run.

Both the risk of being displaced and the consequences of being displaced have been found to vary by individual characteristics. For example, Madden (1988), Farber (1993), Kletzer (1998) have documented that the low-educated are more likely to experience job loss, whereas studies including Farber (1993), Stevens (1997), Farber (2003), provide evidence that re-employment probabilities are lower and that earnings losses are larger among the lower educated. Men appear to be more likely to lose jobs than women (e.g., Seitchik 1991), but there is mixed evidence as to whether there is a sex-difference in labor market outcomes after displacement (Madden 1988; Jacobson et al. 1993; Couch et al. 2009). It has also been documented that subsequent labor market outcomes are worse for older displaced workers (Couch et al. 2009; Couch and Placzek 2010), that effects vary by industry (Jacobson et al. 1993; Couch et al. 2009; Couch and Placzek 2010), and that the long-term effects on earnings depend on the state of the business cycle at the time of displacement (Couch et al. 2011).

Third and finally, there is a literature examining how different groups fare depending on the state of the labor market. Much of this literature has shown that individuals in lowerskilled or otherwise disadvantaged groups are more sensitive to labor market conditions. In one of the earliest studies in the area, Clark and Summers (1981) looked at employment probabilities in different groups, as defined by age, sex and race. They showed that teenage 
workers bore a much larger share of cyclical fluctuations in the US during the 1970s. Among men, the response of teenagers to the unemployment rate was about four times as large as that of the middle-aged. The employment probability of elderly men (those above 65) was also elevated, whereas the response of those between 20 and 64 was very similar all across all ages. There was evidence of a larger sensitivity among non-whites than among whites, but no consistent differences between men and women.

Several studies have exploited differences between regions (e.g., metropolitan statistical areas, MSAs) when studying differential labor market outcomes for demographic groups. For example, Bound and Holzer (1995) found stronger effects for less-educated, lessexperienced and black men in the 1980s when considering MSA-level labor market prospects in the US, using both average hours and wages as outcomes. The results were similar for both men and women. Bartik (1996) focused on the distributional and poverty effects of labor market changes and also found larger effects for young less-educated men, with similar effects for blacks and whites, as well as for men and women.

Hoynes (2000) and Hines et al. (2001) used MSA-level US data between 1975 and the late 90s to compare employment, hours and income, for different skill groups over the business cycle. The skill groups considered were defined by sex, race and educational level. Much in line with previous studies, they found that low skill groups were more affected by economic fluctuations. For example, the employment probability of those with high school or less than high school education responded twice as much to the unemployment rate as those with some college education. College graduates were not significantly affected by the unemployment rate.

Hoynes et al. (2012) also used more recent data including the great recession between 2007 and 2009. The results confirmed that non-white, youth and low-educated, experienced larger employment fluctuations over the business cycle. They also found that men were more affected by the unemployment rate than women. Effects by age were non-linear; they were much larger for individuals between 16 and 20 years of age, but relatively similar for 25 year olds and for 60 year olds. The authors noted that "these dramatic differences in the cyclicality across demographic groups are remarkably stable across three decades of time and across recessionary periods versus expansionary periods.",2, 3

\section{Data}

Our dataset was constructed by combining registers from Statistics Sweden (SCB) and military enlistment records from the Swedish National Service Administration (NSA). These are roughly the same data as those used by Lindqvist and Vestman (2011) and by Lundborg et al. (2014a). ${ }^{4}$ The data include all individuals that enlisted for the Swedish army between 1969 and 1997 and that were born between 1950 and 1979. Since males were obliged by law to undergo the military enlistment procedure during the time period we are studying, our data essentially include all Swedish men. In these years, only about $3 \%$ of each cohort did not enlist. Individuals that were exempt from enlisting included prisoners, individuals convicted of heavy crimes, institutionalized individuals and individuals living abroad. ${ }^{5}$ Military education usually lasted for less than a year and took place between the ages of 18 and 26.

The military enlistment records include extensive information on health and abilities of conscripts at the time of enlistment. In particular, the NSA indicated each conscript's overall health status on an alphabetic scale, which had the purpose of determining the 
individual's suitability with respect to the type of military service; please see Table 1 for detailed information on the determination of the letter indicating overall health. The assignment of this variable was based on a health declaration form that the individual had to bring with him, combined with a general assessment by a physician. Before meeting with the physician, the individual also underwent a number of physical capacity tests and met with a psychologist who, if necessary, could provide the physician with notes regarding the individual's mental health status. ${ }^{6}$ We classify individuals into three groups depending on their overall health status. Individuals that were assigned an "A" by the NSA (about 60\%) are classified as having "good global health," whereas individuals that were assigned a "Y" or a "Z," meaning that they were not allowed to undergo military service, are classified as having "poor global health." Those assigned a letter worse than an "A" but better than a "Y" are classified as having "intermediate global health." 7

Cognitive ability is measured using written tests of logical, verbal, spatial and technical skills. On the basis of the test scores, the individual has been assigned a number on a nine-point scale, approximating a normal distribution. We classify individuals as having a "high cognitive ability" if this number ranges between seven and nine, as having an "intermediate cognitive ability" if this number ranges between four and six and as having a "low cognitive ability" if this number ranges between one and three.

Non-cognitive ability is measured on a similar nine-step scale. This score is assigned by a psychologist, based on a semi-structured interview, with the objective "to assess the conscript's ability to cope with the psychological requirements of the military service and, in

Table 1 Determination of overall health status

\begin{tabular}{|c|c|c|c|c|c|c|c|c|c|c|c|c|}
\hline Overall health & A & $\mathrm{B}$ & C & $\mathrm{D}$ & $E$ & $\mathrm{~F}$ & G & $\mathrm{H}$ & $J$ & $\mathrm{~K}$ & $L$ & $M$ \\
\hline Infection, tumor & 8 & 8 & 6 & 7 & 6 & 6 & 4 & 4 & 5 & 4 & 3 & 3 \\
\hline Inner secretion, blood & 8 & 7 & 6 & 7 & 6 & 6 & 5 & 5 & 5 & 4 & 3 & 3 \\
\hline Mental & 8 & 7 & 6 & 7 & 7 & 6 & 6 & 6 & 5 & 4 & 7 & 3 \\
\hline Nervous system & 8 & 8 & 8 & 7 & 7 & 7 & 6 & 7 & 6 & 7 & 3 & 3 \\
\hline Circulatory system & 8 & 8 & 7 & 7 & 6 & 6 & 4 & 4 & 5 & 4 & 3 & 3 \\
\hline Respiratory system & 8 & 7 & 7 & 7 & 6 & 6 & 4 & 4 & 5 & 4 & 3 & 3 \\
\hline Digestive, urogenital & 8 & 7 & 6 & 7 & 6 & 6 & 4 & 4 & 5 & 4 & 3 & 3 \\
\hline Skin & 8 & 7 & 6 & 7 & 6 & 6 & 5 & 5 & 5 & 4 & 3 & 3 \\
\hline Malformation, injury & 8 & 8 & 8 & 7 & 6 & 6 & 4 & 4 & 6 & 4 & 3 & 3 \\
\hline Allergy & 8 & 7 & 7 & 7 & 6 & 6 & 5 & 6 & 5 & 4 & 3 & 3 \\
\hline Arm & 8 & 8 & 8 & 7 & 7 & 6 & 7 & 7 & 6 & 7 & 3 & 3 \\
\hline Leg & 8 & 8 & 8 & 7 & 6 & 6 & 5 & 4 & 6 & 4 & 3 & 3 \\
\hline Back, abdominal wall & 8 & 8 & 8 & 7 & 6 & 6 & 4 & 5 & 6 & 4 & 3 & 3 \\
\hline Eye & 8 & 7 & 6 & 7 & 6 & 6 & 8 & 4 & 6 & 4 & 3 & 3 \\
\hline Ear & 8 & 7 & 7 & 7 & 7 & 6 & 4 & 8 & 6 & 4 & 3 & 3 \\
\hline Noise sensitivity & 7 & 7 & 7 & 7 & 6 & 6 & 5 & 6 & 6 & 6 & 3 & 3 \\
\hline
\end{tabular}

Along each dimension, the conscript's health is rated on a scale of 1-8, where an 8 indicates no impairment. The table shows minimum requirements for different levels of overall health. A is required for "high mobility positions" such as rifleman, submarine positions and pilot; $B$ combat vehicle and armed positions in general; $C$ for some armed positions and tractor driver; $\mathrm{D}$ for armed positions with reduced requirements, radar seaman and airplane-weapon mechanic; $\mathrm{E}$ for safety technician, motor-electro mechanic, signal mechanic and some telegraphists; F for staff assistant, car mechanic, some motor mechanics, airplane-camera mechanic and armed positions in local defense units; G for mini technician and signal communications, radar and weather service; $\mathrm{H}$ for signal communications ashore; J for shoemaker and assistance in case of war; $\mathrm{K}$ for crypto assistant; $\mathrm{L}$ for enlistment assistant or other assistant; $\mathrm{M}$ for assistant in peacetime. Source: Försvarsmakten (1980) 
extreme case, war." In particular, this implies an assessment of individual characteristics such as willingness to assume responsibility, independence, outgoing character, persistence, emotional stability and power of initiative (Lindqvist and Vestman 2011). Analogous to our treatment of cognitive ability, we classify individuals as having a "high non-cognitive ability," an "intermediate non-cognitive ability," or a "low non-cognitive ability," depending upon if their score falls between seven and nine, between four and six, or between one and three.

From the registers, we have obtained individual-level data on education and earnings from work. ${ }^{8}$ These data are bi-yearly and span the period between 1999 and 2007, which means that we observe outcomes for individuals that are between 20 and 57 years of age. As noted, health and skills are measured at the age of 18 or 19 so they do not depend on observed labor market outcomes. Educational attainment is expressed in terms of the highest degree attained, and we group individuals by whether they have primary education only, secondary education, or some tertiary education. ${ }^{9}$

We classify individuals as being employed if they have positive income from work during the current year. Having no income from work is not synonymous with being unemployed at a specific point in time, but reflects the combination of individuals that are unable to find any employment during the entire year and individuals that are more or less voluntarily non-employed. We focus on this employment measure since it is less arbitrary than using some positive threshold and since the share of individuals with no income from work is relatively high. ${ }^{10}$

We measure local labor market conditions by unemployment statistics from the Swedish Labor Market Board (Ams). These data refer to the number of unemployed working-age individuals (aged 16-64) in November of each year, divided by the population in the same age group. The geographical unit of observation is the local labor market region, as defined by Statistics Sweden and based on commuting patterns in 1999. There are 92 local labor market regions. ${ }^{11}$

Our analysis uses all native male Swedes for which there is non-missing information on global health in the military enlistment records. This indicates that the individual actually underwent the military enlistment procedure. For cognitive ability, non-cognitive ability and education, we create dummies indicating the presence of missing information.

Table 2 displays descriptive statistics for our main estimation sample. There are 1,121,138 individuals and as almost every individual is being observed five times with non-missing information on the local unemployment rate, our estimation sample includes 5,533,393 observations. The overall rate of employment is 88 and $78 \%$ of all observations and is associated with incomes of at least SEK 100,000. In addition to the means of the variables used, the table shows the employment probabilities for individuals belonging to the different health and skill categories. Individuals in good or intermediate health or with high or intermediate skills or education and employment probabilities are at least $90 \%$. Whether an individual belongs to the top or intermediate group with respect to these outcomes makes relatively little difference for his employment probability. For individuals in poor health or with low skills, employment probabilities are only about $80 \%$.

\section{Empirical strategy}

Our estimations are based on the following equation, where we cluster by labor market region. The outcome variable is an employment indicator (or, in some specifications, an indicator for having an income above some positive threshold) for individual $i$ in year $t$. $Y$ 
Table 2 Descriptive statistics

\begin{tabular}{llll}
\hline & Mean & Std. & $\begin{array}{l}\text { Employment by } \\
\text { category }\end{array}$ \\
\hline Year of birth & 1965 & 8 & - \\
Unemployment rate & 0.05 & 0.01 & - \\
Employment (positive income) & 0.88 & - & 1.00 \\
Income at least SEK 100,000 & 0.78 & - & 1.00 \\
Good health & 0.58 & - & 0.90 \\
Intermediate health & 0.30 & - & 0.89 \\
Poor health & 0.12 & - & 0.78 \\
High cognitive ability & 0.25 & - & 0.91 \\
Medium cognitive ability & 0.53 & - & 0.89 \\
Low cognitive ability & 0.20 & - & 0.84 \\
High non-cog. ability & 0.21 & - & 0.91 \\
Medium non-cog. ability & 0.56 & - & 0.90 \\
Low non-cog. ability & 0.17 & - & 0.81 \\
Tertiary education & 0.32 & - & 0.94 \\
Secondary education & 0.53 & - & 0.89 \\
Primary education & 0.14 & $5,533,393$ & 0.80 \\
Individual-year observations & & & \\
\hline
\end{tabular}

includes dummies for each year, $R$ includes dummies for region, $B Y$ includes dummies for each birth year and $A$ represents one or several indicators for health or skills, including indicators for missing information. The specifications are similar to the ones employed by previous studies such as Hoynes (2000), Hoynes et al. (2012), Biddle and Hamermesh (2013). ${ }^{12,}{ }^{13}$ We also include a (standardized) linear birth year trend, interacted with the unemployment rate, to account for the possibility that different cohorts are affected differently by unemployment.

$$
\begin{aligned}
& \mathrm{E}_{\mathrm{it}}=\mathrm{a}+\mathrm{b}_{0} * \mathrm{Y}_{\mathrm{t}}+\mathrm{b}_{1} * \mathrm{R}_{\mathrm{it}}+\mathrm{b}_{2} * \mathrm{BY}_{\mathrm{i}}+\mathrm{b}_{3} * \mathrm{UR}_{\mathrm{it}}+\mathrm{b}_{4} * \mathrm{~A}_{\mathrm{i}} * \mathrm{UR}_{\mathrm{it}} \\
& +\mathrm{b}_{5} * \mathrm{~A}_{\mathrm{i}} * \mathrm{Y}_{\mathrm{t}}+\mathrm{b}_{6} * \mathrm{~A}_{\mathrm{i}} * \mathrm{R}_{\mathrm{it}}+\mathrm{b}_{7} * \mathrm{BT}_{\mathrm{i}} * \mathrm{UR}_{\mathrm{it}}+\mathrm{e}_{\mathrm{it}}
\end{aligned}
$$

The coefficient $b_{3}$ measures the effect of the unemployment rate among those with good health and skills, whereas for individuals with worse health or lower skills, the effect of the unemployment rate is given by $b_{3}$ plus (some components of) $b_{4}$. Our primary interest lies in the interaction effects $b_{4}$.

Since we include both year and region fixed effects, our empirical strategy exploits temporary deviations in unemployment from regional averages, as well as geographical deviations from national averages. National policies are thus of no concern, and permanently worse long-run public finances in regions with higher unemployment are accounted for. ${ }^{14}$

In Fig. 1, we illustrate the evolution of the local unemployment rates in Sweden over the time period of study. The median unemployment rate is relatively stable at around $6 \%$ over the time period. Although the local unemployment rates tend to be rather close to the median, there are also regions with considerably lower or higher unemployment rates; the minimum unemployment rates are about 2 to $3 \%$, whereas the maximum rates range between 9 and 15\%. 


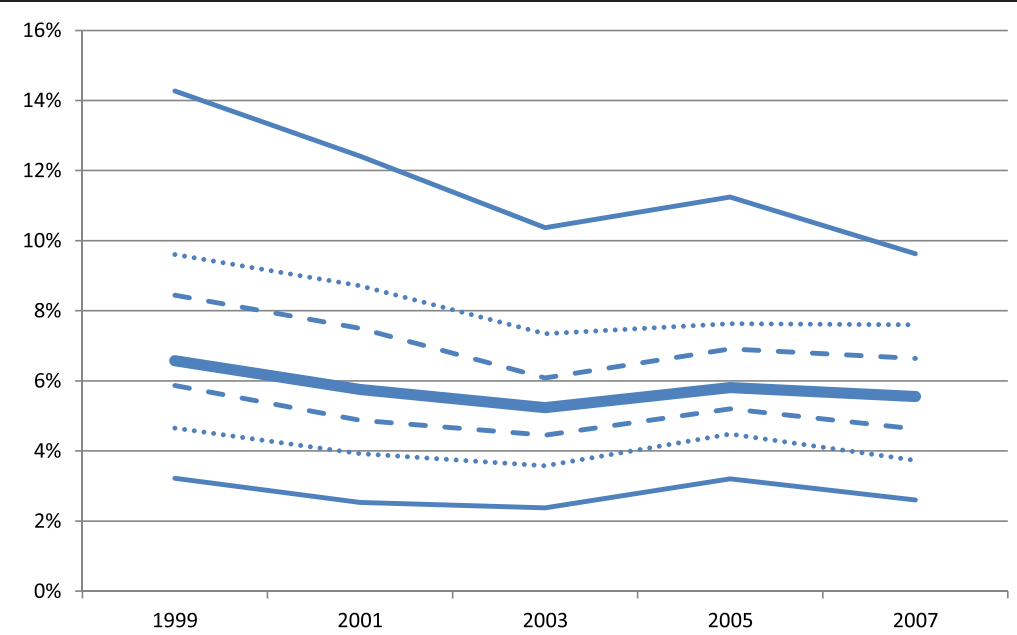

Fig. 1 Local unemployment rates over the time period of study. Max; 90 percentile; 75 percentile; Median; 25 percentile; 10 percentile, Min

\section{Results}

\subsection{The employment sensitivity of the lower skilled}

Table 3 shows our main results, where employment in the sense of having a positive income is being linked to the local unemployment rate. First of all, column A suggests that a one percentage point increase in the unemployment rate is associated with a 0.3

Table 3 Employment by health/skills - main results

\begin{tabular}{|c|c|c|c|c|c|}
\hline & (A) & (B) & (C) & (D) & (E) \\
\hline \multirow[t]{2}{*}{ Unemployment rate } & $-0.285^{\mathrm{a}}$ & -0.202 & -0.153 & -0.281 & -0.174 \\
\hline & $(0.126)$ & $(0.132)$ & $(0.211)$ & (0.219) & $(0.250)$ \\
\hline \multicolumn{6}{|l|}{ UR interacted with: } \\
\hline \multirow[t]{2}{*}{ Intermediate health } & & $-0.090^{b}$ & & & -0.047 \\
\hline & & $(0.049)$ & & & $(0.047)$ \\
\hline \multirow[t]{2}{*}{ Poor health } & & $-0.394^{c}$ & & & $-0.346^{c}$ \\
\hline & & $(0.092)$ & & & (0.129) \\
\hline \multirow[t]{2}{*}{ Medium cognitive ability } & & & -0.006 & & -0.010 \\
\hline & & & $(0.105)$ & & $(0.084)$ \\
\hline \multirow[t]{2}{*}{ Low cognitive ability } & & & -0.051 & & -0.027 \\
\hline & & & $(0.154)$ & & $(0.134)$ \\
\hline \multirow[t]{2}{*}{ Medium non-cog. ability } & & & -0.083 & & -0.063 \\
\hline & & & $(0.066)$ & & $(0.069)$ \\
\hline \multirow[t]{2}{*}{ Low non-cog. ability } & & & $-0.410^{c}$ & & $-0.308^{a}$ \\
\hline & & & $(0.148)$ & & $(0.142)$ \\
\hline \multirow[t]{2}{*}{ Secondary education } & & & & -0.084 & -0.027 \\
\hline & & & & $(0.134)$ & $(0.116)$ \\
\hline \multirow[t]{2}{*}{ Primary education } & & & & -0.090 & 0.075 \\
\hline & & & & $(0.126)$ & $(0.125)$ \\
\hline Observations & & & $5,533,393$ & & \\
\hline
\end{tabular}

Standard errors are clustered at the regional level and are displayed in parentheses ${ }^{a} \%$ significance, ${ }^{b}$ indicates $10 \%$ significance and ${ }^{\mathrm{c}} 1 \%$ significance 
percentage point lower probability of being employed (that is, receiving income from work) during a year. As expected, the coefficient is lower than one, as unemployment typically lasts for less than a year. ${ }^{15}$

In column B, we include interactions with the health categories. We find that individuals in worse health are more sensitive to the unemployment rate. The main effect of unemployment shows that the employment probability for individuals in good health decreases by about 0.2 percentage points per percentage point increase in unemployment, but the main effect is, as will also be the case in the rest of the analysis, not statistically significant. This is in line with Hines et al. (2001), who found no significant effect of the unemployment rate on the most advantaged individuals (in their case, college graduates). For individuals in intermediate health, there is an additional penalty of 0.1 , whereas for individuals in poor health, the estimate suggests an additional penalty of almost 0.4 percentage points. ${ }^{16}$

Column $\mathrm{C}$ examines differential impacts by cognitive and non-cognitive ability. There is little evidence of differential effects by cognitive ability. Instead, our results suggest an additional penalty amounting to a 0.4 percentage point lower employment probability for individuals with a low non-cognitive ability.

Column D shows results for different educational groups. The point estimates for primary as well as secondary education are about -0.1, but they are not statistically significant. This contrasts with previous studies, such as Hines et al. (2001) and Hoynes et al. (2012), who found a larger sensitivity to unemployment among the less educated in the US. Potentially, the insignificant results in the Swedish context could be attributed to the much stronger employment protection legislation, which makes it relatively hard for employers to lay off individuals simply because of a low productivity. If this explanation holds, one would suspect that the differences in responses by other characteristics (health and non-cognitive ability) could be even stronger in the US, a question for future research to determine.

Column E shows that results do not change much when all dimensions of health and skills are accounted for at the same time. For example, there is a large effect for poor health, which is similar to the one obtained before. The same is true for noncognitive ability, whereas there is little evidence that unemployment would have differential effects depending on individuals' cognitive skills or education. While our results pertain to somewhat different outcomes, these patterns are broadly in line with those of previous studies, suggesting that lower skilled individuals may be much more sensitive to local unemployment rates than high skilled ones. Moreover, we find indicative evidence of non-linear effects, suggesting that those with low skills are hit harder than those with high skills, whereas there is little or no difference between high-skilled and medium-skilled individuals. Hoynes et al. (2012) documented such a non-linear pattern for age (but not for education).

Table 4 reproduces our above results, but removes the region-specific effects in order to potentially increase variation. The main effects of unemployment now become significant in several cases. We again find significant unemployment penalties for individuals with poor health or a low non-cognitive ability, and the effects are somewhat stronger than those obtained when accounting for region effects. There is also significant evidence that individuals with a medium non-cognitive ability are more affected by the unemployment rate than the baseline group. ${ }^{17}$ 
Table 4 Employment by health/skills - without region effects

\begin{tabular}{|c|c|c|c|c|c|}
\hline & (A) & (B) & (C) & (D) & (E) \\
\hline \multirow[t]{2}{*}{ Unemployment rate } & $-0.559^{a}$ & $-0.344^{b}$ & -0.082 & $-0.200^{c}$ & 0.033 \\
\hline & $(0.123)$ & $(0.146)$ & $(0.146)$ & $(0.116)$ & $(0.159)$ \\
\hline \multicolumn{6}{|l|}{ UR interacted with: } \\
\hline \multirow[t]{2}{*}{ Intermediate health } & & $-0.163^{\mathrm{a}}$ & & & -0.066 \\
\hline & & $(0.043)$ & & & $(0.052)$ \\
\hline \multirow[t]{2}{*}{ Poor health } & & $-0.610^{b}$ & & & $-0.409^{b}$ \\
\hline & & $(0.254)$ & & & $(0.189)$ \\
\hline \multirow[t]{2}{*}{ Medium cognitive ability } & & & 0.076 & & 0.018 \\
\hline & & & $(0.087)$ & & $(0.051)$ \\
\hline \multirow[t]{2}{*}{ Low cognitive ability } & & & 0.095 & & -0.056 \\
\hline & & & $(0.159)$ & & $-0.208^{\mathrm{a}}$ \\
\hline \multirow[t]{2}{*}{ Medium non-cog. ability } & & & $-0.198^{a}$ & & $(0.059)$ \\
\hline & & & $(0.071)$ & & $-0.590^{\mathrm{a}}$ \\
\hline \multirow[t]{2}{*}{ Low non-cog. ability } & & & $-0.564^{\mathrm{a}}$ & & $(0.129)$ \\
\hline & & & $(0.101)$ & & $-0.208^{\mathrm{a}}$ \\
\hline \multirow[t]{2}{*}{ Secondary education } & & & & -0.098 & 0.100 \\
\hline & & & & $(0.219)$ & $(0.225)$ \\
\hline \multirow[t]{2}{*}{ Primary education } & & & & -0.500 & -0.129 \\
\hline & & & & $(0.416)$ & $(0.451)$ \\
\hline Observations & & & $5,533,393$ & & \\
\hline
\end{tabular}

Standard errors are clustered at the regional level and are displayed in parentheses ${ }^{a} 1 \%$ significance, ${ }^{b} \%$ significance and ${ }^{c}$ indicates $10 \%$ significance

\subsection{Alternative employment thresholds}

Defining employment as having a positive income in a year is a weak criterion because some individuals with a positive income may only work for a small part of the year or may be part-time unemployed. We consider here alternative specifications where the outcome variable is an indicator taking the value of one when individuals have an annual income exceeding some higher amount. We use thresholds up to SEK 100,000, deflated to $1999 .^{18}$ Results are shown in Table 5.

Interestingly, the result for health only shows up at the most conservative threshold of SEK 0. For higher thresholds, the interaction between poor health and unemployment becomes insignificant and approaches zero. Clearly, a high unemployment rate mostly affects sickly individuals by leaving them without employment throughout the year.

The result for non-cognitive ability is found throughout, but is somewhat weaker at the lowest margin. Moreover, at all thresholds, except for the lowest one, there is evidence that individuals with a medium non-cognitive ability are penalized by a higher unemployment rate. As before, there is no evidence of differential effects by educational attainment or cognitive ability.

In addition to studying employment or earnings above certain thresholds, it is of interest to study (log) earnings as an outcome. This measure captures a combination of hours worked and wages per hour, but the disadvantage is that we cannot distinguish between these two. There is also a selection issue since those with zero earnings are dropped, potentially leading to less significant results. Nevertheless, Table 6 shows results for this outcome. The earnings of those with a low cognitive ability or with a 
Table 5 Alternative employment thresholds

\begin{tabular}{|c|c|c|c|c|c|c|c|c|c|c|c|}
\hline & 0 & 10,000 & 20,000 & 30,000 & 40,000 & 50,000 & 60,000 & 70,000 & 80,000 & 90,000 & 100,000 \\
\hline \multirow[t]{2}{*}{ Unemployment rate } & -0.174 & -0.133 & -0.074 & 0.043 & 0.107 & 0.128 & 0.138 & 0.207 & 0.170 & 0.216 & 0.220 \\
\hline & $(0.250)$ & $(0.330)$ & $(0.425)$ & $(0.590)$ & $(0.724)$ & $(0.773)$ & $(0.812)$ & $(0.829)$ & $(0.832)$ & (0.838) & $(0.830)$ \\
\hline \multicolumn{12}{|l|}{ UR interacted with: } \\
\hline \multirow[t]{2}{*}{ Intermediate health } & -0.047 & -0.002 & -0.000 & -0.004 & -0.001 & -0.034 & -0.059 & -0.081 & -0.058 & -0.071 & -0.067 \\
\hline & $(0.047)$ & $(0.056)$ & $(0.060)$ & $(0.073)$ & $(0.075)$ & $(0.080)$ & $(0.084)$ & (0.089) & $(0.095)$ & $(0.102)$ & $(0.104)$ \\
\hline \multirow[t]{2}{*}{ Poor health } & $-0.346^{\mathrm{a}}$ & -0.211 & -0.218 & -0.178 & -0.166 & -0.158 & -0.129 & -0.089 & -0.118 & -0.069 & -0.113 \\
\hline & $(0.129)$ & (0.199) & $(0.186)$ & $(0.216)$ & $(0.215)$ & $(0.198)$ & $(0.211)$ & $(0.228)$ & $(0.223)$ & $(0.228)$ & $(0.230)$ \\
\hline \multirow[t]{2}{*}{ Medium cognitive ability } & -0.010 & -0.015 & -0.054 & -0.110 & -0.108 & -0.119 & -0.102 & -0.181 & -0.196 & -0.202 & -0.210 \\
\hline & $(0.084)$ & $(0.099)$ & $(0.126)$ & $(0.171)$ & $(0.200)$ & $(0.219)$ & $(0.237)$ & $(0.248)$ & $(0.245)$ & $(0.248)$ & $(0.250)$ \\
\hline \multirow[t]{2}{*}{ Low cognitive ability } & -0.027 & -0.069 & -0.123 & -0.204 & -0.235 & -0.269 & -0.258 & -0.375 & -0.407 & -0.448 & -0.473 \\
\hline & $(0.134)$ & $(0.146)$ & $(0.177)$ & $(0.220)$ & $(0.262)$ & $(0.275)$ & $(0.292)$ & $(0.294)$ & $(0.300)$ & $(0.306)$ & $(0.301)$ \\
\hline \multirow[t]{2}{*}{ Medium non-cog. ability } & -0.063 & $-0.185^{\mathrm{b}}$ & $-0.155^{c}$ & $-0.191^{\mathrm{b}}$ & $-0.256^{\mathrm{a}}$ & $-0.263^{\mathrm{a}}$ & $-0.242^{\mathrm{a}}$ & $-0.254^{\mathrm{a}}$ & $-0.236^{\mathrm{a}}$ & $-0.246^{b}$ & $-0.272^{\mathrm{a}}$ \\
\hline & $(0.069)$ & $(0.084)$ & $(0.089)$ & $(0.093)$ & $(0.083)$ & $(0.084)$ & $(0.081)$ & $(0.088)$ & $(0.088)$ & $(0.094)$ & $(0.094)$ \\
\hline \multirow[t]{2}{*}{ Low non-cog. ability } & $-0.308^{b}$ & $-0.504^{\mathrm{a}}$ & $-0.510^{\mathrm{a}}$ & $-0.587^{\mathrm{a}}$ & $-0.595^{\mathrm{a}}$ & $-0.597^{a}$ & $-0.584^{\mathrm{a}}$ & $-0.621^{\mathrm{a}}$ & $-0.568^{\mathrm{a}}$ & $-0.592^{\mathrm{a}}$ & $-0.582^{\mathrm{a}}$ \\
\hline & $(0.142)$ & $(0.147)$ & $(0.170)$ & $(0.168)$ & $(0.154)$ & $(0.160)$ & $(0.147)$ & $(0.143)$ & $(0.152)$ & $(0.156)$ & $(0.151)$ \\
\hline \multirow[t]{2}{*}{ Secondary education } & -0.027 & -0.062 & -0.145 & -0.207 & -0.231 & -0.240 & -0.336 & -0.368 & -0.365 & -0.434 & -0.465 \\
\hline & $(0.116)$ & $(0.177)$ & $(0.255)$ & $(0.392)$ & $(0.485)$ & $(0.535)$ & $(0.557)$ & $(0.550)$ & $(0.544)$ & $(0.547)$ & $(0.538)$ \\
\hline \multirow[t]{2}{*}{ Primary education } & 0.075 & -0.008 & -0.083 & -0.095 & -0.130 & -0.150 & -0.195 & -0.186 & -0.198 & -0.199 & -0.195 \\
\hline & $(0.125)$ & $(0.185)$ & $(0.269)$ & $(0.397)$ & $(0.485)$ & $(0.547)$ & $(0.584)$ & $(0.596)$ & $(0.604)$ & $(0.634)$ & $(0.646)$ \\
\hline Observations & & & & & & $5,533,393$ & & & & & \\
\hline
\end{tabular}

Standard errors are clustered at the regional level and are displayed in parentheses

${ }^{\mathrm{a}} 1 \%$ significance, ${ }^{\mathrm{b}_{5}} \mathrm{\%}$ significance and ${ }^{\mathrm{c}}$ indicates $10 \%$ significance 
Table 6 Log earnings by health/skills

\begin{tabular}{|c|c|c|c|c|c|}
\hline & (A) & (B) & (C) & (D) & (E) \\
\hline \multirow[t]{2}{*}{ Unemployment rate } & -0.415 & -0.223 & 1.318 & 0.197 & 1.223 \\
\hline & $(0.498)$ & $(0.587)$ & $(1.343)$ & $(1.473)$ & $(1.680)$ \\
\hline \multicolumn{6}{|l|}{ UR interacted with: } \\
\hline \multirow[t]{2}{*}{ Intermediate health } & & -0.437 & & & -0.107 \\
\hline & & $(0.331)$ & & & $(0.308)$ \\
\hline \multirow[t]{2}{*}{ Poor health } & & -0.346 & & & 0.223 \\
\hline & & $(0.781)$ & & & $(0.847)$ \\
\hline \multirow[t]{2}{*}{ Medium cognitive ability } & & & -0.930 & & -0.562 \\
\hline & & & $(0.892)$ & & $(0.539)$ \\
\hline \multirow[t]{2}{*}{ Low cognitive ability } & & & -1.771 & & $-1.061^{\mathrm{a}}$ \\
\hline & & & $(1.148)$ & & $(0.637)$ \\
\hline \multirow[t]{2}{*}{ Medium non-cog. ability } & & & $-1.332^{b}$ & & $-1.149^{b}$ \\
\hline & & & $(0.333)$ & & $(0.270)$ \\
\hline \multirow[t]{2}{*}{ Low non-cog. ability } & & & $-1.870^{\mathrm{b}}$ & & $-1.752^{b}$ \\
\hline & & & $(0.399)$ & & $(0.404)$ \\
\hline \multirow[t]{2}{*}{ Secondary education } & & & & -1.617 & -0.945 \\
\hline & & & & $(1.348)$ & $(1.262)$ \\
\hline \multirow[t]{2}{*}{ Primary education } & & & & -1.398 & -0.483 \\
\hline & & & & $(1.667)$ & $(1.618)$ \\
\hline Observations & & & $4,940,192$ & & \\
\hline
\end{tabular}

Standard errors are clustered at the regional level and are displayed in parentheses ${ }^{a}$ indicates $10 \%$ significance, ${ }^{b} 1 \%$ significance and ${ }^{c} 5 \%$ significance

medium or low non-cognitive ability are found to respond stronger to the unemployment rate.

\subsection{Mobility}

So far, we have assumed that the unemployment rate that an individual faces is exogenous and not determined by individual choices. This means that we have ignored the possibility of geographical mobility. Eliasson and Westerlund (2009) have shown that geographical mobility in Sweden has increased since the 1980s and that during the time period we study between 2 and $2.5 \%$ of the population moved to another local labor region every year. While these numbers are still relatively low, they show that the unemployment rates faced by individuals are not fully exogenous.

The reasons why individuals move (within a country) are most likely diverse and include factors such as family formation and breakup, changing preferences and changing labor market opportunities. Individuals may move to another region because they have found, or expect to find, a more attractive job there (a "pull factor") or because they are not able to find an acceptable job in their current labor market region (a "push factor"). It is important to note that decisions to move are not necessarily well-informed and that some groups may have a hard time predicting where job opportunities are better. Several studies have documented, however, that mobility responds to employment opportunities and that (at least) individuals that are unemployed are more likely to move 
to regions with better opportunities (e.g., Pissarides and Wadsworth 1989; Westerlund 1997; Eliasson and Westerlund 2009; Rabe and Taylor 2012).

If mobility responses differ between health and skill groups, some of our results could potentially be driven by differential mobility rather than by differential employment responses. Individuals with poor health or low skills may be less likely to move because they are more dependent on families and networks or because they face smaller economic incentives to take a job. If they actually do move to another location, their reliance on families and networks may still imply that they do not settle down in a region with a large supply of jobs. On the other hand, moving to another region may be thought of as a "search strategy of last resort," and in that case, disadvantaged individuals may be more likely to move (and to move to a low-unemployment region) in order to find an acceptable job.

In column A of Table 7, we report results from regressions, which are similar to those used before, but the outcome variable has been replaced by an indicator taking the value of one if the individual moves in the subsequent time interval; that is, if the region of residence 2 years ahead in time differs from the current region of residence. ${ }^{19}$ The results provide little evidence that mobility would react to unemployment; both the main effect of unemployment and all interactions but one (the one with medium non-cognitive ability) are

Table 7 Mobility

\begin{tabular}{|c|c|c|c|c|}
\hline & \multicolumn{2}{|c|}{ Mobility decision } & \multicolumn{2}{|c|}{ Unemloyment } \\
\hline & (A) & (B) & (C) & (D) \\
\hline \multirow[t]{2}{*}{ Unemployment rate } & 0.813 & $1.744^{\mathrm{a}}$ & $16.936^{\mathrm{a}}$ & $27.201^{\mathrm{a}}$ \\
\hline & $(0.624)$ & $(0.364)$ & $(2.349)$ & $(3.083)$ \\
\hline \multicolumn{5}{|l|}{ UR interacted with: } \\
\hline \multirow[t]{2}{*}{ Intermediate health } & -0.004 & $-0.097^{\mathrm{a}}$ & $-1.090^{\mathrm{a}}$ & $-0.877^{\mathrm{a}}$ \\
\hline & $(0.055)$ & $(0.027)$ & $(0.392)$ & $(0.224)$ \\
\hline \multirow[t]{2}{*}{ Poor health } & 0.047 & 0.106 & -1.103 & -0.212 \\
\hline & $(0.130)$ & $(0.075)$ & $(0.753)$ & $(0.546)$ \\
\hline \multirow[t]{2}{*}{ Medium cognitive ability } & -0.097 & $-0.296^{a}$ & -0.532 & $-1.534^{\mathrm{a}}$ \\
\hline & $(0.139)$ & $(0.064)$ & $(0.645)$ & $(0.397)$ \\
\hline \multirow[t]{2}{*}{ Low cognitive ability } & -0.245 & $-0.387^{\mathrm{a}}$ & -0.771 & $-2.663^{\mathrm{a}}$ \\
\hline & $(0.194)$ & $(0.081)$ & $(0.906)$ & $(0.719)$ \\
\hline \multirow[t]{2}{*}{ Medium non-cog. ability } & $-0.249^{b}$ & $-0.236^{\mathrm{a}}$ & 0.557 & $-0.721^{\mathrm{a}}$ \\
\hline & $(0.146)$ & $(0.046)$ & $(0.483)$ & $(0.203)$ \\
\hline \multirow[t]{2}{*}{ Low non-cog. ability } & -0.239 & $-0.127^{\mathrm{a}}$ & -0.143 & $-1.145^{\mathrm{a}}$ \\
\hline & $(0.156)$ & $(0.040)$ & $(0.530)$ & $(0.287)$ \\
\hline \multirow[t]{2}{*}{ Secondary education } & -0.261 & $-0.893^{\mathrm{a}}$ & 0.028 & $-3.731^{\mathrm{a}}$ \\
\hline & $(0.340)$ & $(0.306)$ & $(0.845)$ & $(0.586)$ \\
\hline \multirow[t]{2}{*}{ Primary education } & -0.104 & $-0.737^{\mathrm{a}}$ & 1.104 & $-1.654^{\mathrm{a}}$ \\
\hline & $(0.344)$ & $(0.271)$ & $(0.958)$ & $(0.449)$ \\
\hline Region effects & $x$ & & $x$ & \\
\hline Observations & \multicolumn{2}{|c|}{$4,437,246$} & \multicolumn{2}{|c|}{227,263} \\
\hline
\end{tabular}

The outcome variable in column $\mathrm{A}$ and $\mathrm{B}$ is an indicator taking the value one if the individual moves between the current and next time period ( 2 years later). In column $C$ and $D$, the sample is restricted to movers and the outcome variable is a dummy taking the value one if the individual moves to a region with lower unemployment. Columns $B$ and $D$ do not account for region effects. Standard errors are clustered at the regional level and are displayed in parentheses ${ }^{\mathrm{a}} 1 \%$ significance, ${ }^{\mathrm{b}}$ indicates $10 \%$ significance and ${ }^{\mathrm{c}} 5 \%$ significance 
statistically insignificant. However, since precision is rather low, we also report results where region effects are not being accounted for; see column $B{ }^{20}$ These results suggest that a higher unemployment rate leads to more mobility and that individuals with lower cognitive abilities, with lower non-cognitive abilities, with a lower education and worse (or at least intermediate) health are, compared to the baseline group, less prone to move when the unemployment rate rises. This result is in line with Bound and Holzer (1995), who found that the lower skilled (younger and less educated) individuals were less likely to respond to poor labor market prospects by moving.

We also explore whether people move to more economically favorable areas. Here, we limit the sample to observations where the individual moves to another region between the current and next time period. In column $\mathrm{C}$ of Table 7, the outcome variable is a dummy taking the value of one if the unemployment rate experienced in the next time period is lower than the one experienced in the current time period. When health and skills are good, we find that an increase in the local unemployment rate by one percentage point is associated with a 17 percentage point higher probability of moving to a region with a lower unemployment. Among the interactions, only one is significant, suggesting that those with intermediate health are somewhat less likely to move to a region with a lower unemployment rate. Dropping the region effects (column D), the main effect rises to 27 percentage points, and almost all interactions significantly suggest that the disadvantaged are somewhat less likely to move to regions where the unemployment rate is lower.

One should note that the results on the mobility decision may understate the true the effects in the presence of return migration. If individuals find labor market prospects to be poor in the current year, they may decide to temporarily move to another region and then return to their home region within 2 years. In this case, we would not observe them as movers. However, unemployment would be a choice variable and our estimates of the labor market consequences of unemployment would be potentially biased.

We then take two different approaches to deal with the possibility that some of our results are driven by mobility. First, in Table 8, we report results for employment where we have excluded all individuals that moved to another labor market region during the time period from 1999 to 2007. This reduces the sample by about 15\%. As it turns out, the results are similar to those obtained before. In particular, individuals in poor health or with a low non-cognitive ability have worse outcomes and the estimated effects are just slightly smaller than before.

Simply excluding individuals who moved over the time period of study could induce endogeneity problems if employment and mobility have common determinants. An alternative would be to exclude individuals based on some characteristic that is related to mobility but not directly related to employment. Our second approach to deal with the mobility issue is, therefore, to exclude individuals with a prior mobility experience. Previous literature (e.g., Da Vanzo 1983; Holmlund 1984; Westerlund and Wyzan 1995; Westerlund 1997) has suggested that individuals that move in one period are more likely to move in subsequent periods, which motivates this choice. Table 9 reports results where we excluded individuals not moving between their military enlistment and 1999. This restriction reduces the sample size by $24 \%$. Results are again similar. 
Table 8 Non-movers

\begin{tabular}{|c|c|c|c|c|c|}
\hline & (A) & (B) & (C) & (D) & (E) \\
\hline \multirow[t]{2}{*}{ Unemployment rate } & $-0.300^{a}$ & $-0.226^{b}$ & -0.227 & $-0.364^{\mathrm{a}}$ & -0.275 \\
\hline & $(0.136)$ & $(0.126)$ & $(0.165)$ & $(0.153)$ & $(0.177)$ \\
\hline \multicolumn{6}{|l|}{ UR interacted with: } \\
\hline \multirow[t]{2}{*}{ Intermediate health } & & -0.062 & & & -0.023 \\
\hline & & $(0.044)$ & & & $(0.043)$ \\
\hline \multirow[t]{2}{*}{ Poor health } & & $-0.364^{c}$ & & & $-0.327^{\mathrm{a}}$ \\
\hline & & $(0.131)$ & & & $(0.162)$ \\
\hline \multirow[t]{2}{*}{ Medium cognitive ability } & & & 0.038 & & 0.014 \\
\hline & & & $(0.083)$ & & $(0.079)$ \\
\hline \multirow[t]{2}{*}{ Low cognitive ability } & & & 0.042 & & 0.021 \\
\hline & & & $(0.112)$ & & $(0.121)$ \\
\hline \multirow[t]{2}{*}{ Medium non-cog. ability } & & & -0.055 & & -0.050 \\
\hline & & & $(0.065)$ & & $(0.064)$ \\
\hline \multirow[t]{2}{*}{ Low non-cog. ability } & & & $-0.382^{a}$ & & $-0.301^{\mathrm{a}}$ \\
\hline & & & $(0.168)$ & & $(0.140)$ \\
\hline \multirow[t]{2}{*}{ Secondary education } & & & & 0.015 & 0.050 \\
\hline & & & & $(0.092)$ & $(0.079)$ \\
\hline \multirow[t]{2}{*}{ Primary education } & & & & 0.053 & 0.178 \\
\hline & & & & $(0.135)$ & $(0.134)$ \\
\hline Observations & & & $4,734,732$ & & \\
\hline
\end{tabular}

Standard errors are clustered at the regional level and are displayed in parentheses ${ }^{a} \%$ significance, ${ }^{b}$ indicates $10 \%$ significance and ${ }^{\mathrm{c}} 1 \%$ significance

\subsection{Accounting for occupations}

If individuals choose occupations in a way that is related to their health and skills, our results could be due to differential employment variability between occupational groups. Hoynes et al. (2012) showed that their results for the 2007 recession were largely driven by the sorting of individuals into 30 industry-occupation cells. Our data does not include indicators for industry, but instead about 100 occupational categories. ${ }^{21}$ We thus rerun our main analysis, controlling for occupations, their interactions with year dummies and their interactions with the unemployment rate. ${ }^{22}$ Results are reported in Table $10 .{ }^{23}$

We find that accounting for occupation does not eliminate our results, as would have been the case if our findings were simply driven by disadvantaged individuals sorting into occupations that are more sensitive to the unemployment rate. Instead, our results tend to get stronger, suggesting that the net effects of a lower ability that were previously estimated arose from the combination a strong direct sensitivity to the unemployment rate and a sorting into occupations that are less sensitive to unemployment. In particular, all the four interactions between unemployment and cognitive or non-cognitive ability have now turned statistically significant.

Our results also suggest that individuals with less education are more sensitive to the unemployment rate once the sorting into occupations is accounted for. However, this is only the case when not accounting for abilities. The differential effects by educational attainment so much highlighted in the literature are clearly less important than those by the other characteristics that we examine. 
Table 9 Immobiles

\begin{tabular}{|c|c|c|c|c|c|}
\hline VARIABLES & (A) & (B) & (C) & (D) & (E) \\
\hline \multirow[t]{2}{*}{ Unemployment rate } & $-0.301^{\mathrm{a}}$ & $-0.234^{b}$ & -0.244 & $-0.408^{\mathrm{a}}$ & -0.324 \\
\hline & $(0.110)$ & $(0.114)$ & $(0.168)$ & $(0.158)$ & $(0.198)$ \\
\hline \multicolumn{6}{|l|}{ UR interacted with: } \\
\hline \multirow[t]{2}{*}{ Intermediate health } & & $-0.111^{\mathrm{a}}$ & & & -0.070 \\
\hline & & $(0.056)$ & & & $(0.059)$ \\
\hline \multirow[t]{2}{*}{ Poor health } & & $-0.298^{c}$ & & & $-0.284^{\mathrm{a}}$ \\
\hline & & $(0.097)$ & & & $(0.136)$ \\
\hline \multirow[t]{2}{*}{ Medium cognitive ability } & & & 0.093 & & 0.054 \\
\hline & & & $(0.089)$ & & $(0.090)$ \\
\hline \multirow[t]{2}{*}{ Low cognitive ability } & & & 0.013 & & -0.024 \\
\hline & & & $(0.125)$ & & $(0.142)$ \\
\hline \multirow[t]{2}{*}{ Medium non-cog. ability } & & & -0.110 & & -0.105 \\
\hline & & & $(0.069)$ & & $(0.074)$ \\
\hline \multirow[t]{2}{*}{ Low non-cog. ability } & & & $-0.372^{\mathrm{a}}$ & & $-0.310^{b}$ \\
\hline & & & $(0.172)$ & & $(0.165)$ \\
\hline \multirow[t]{2}{*}{ Secondary education } & & & & 0.051 & 0.112 \\
\hline & & & & $(0.105)$ & $(0.100)$ \\
\hline \multirow[t]{2}{*}{ Primary education } & & & & 0.083 & 0.243 \\
\hline & & & & $(0.139)$ & $(0.158)$ \\
\hline Observations & & & $4,201,427$ & & \\
\hline
\end{tabular}

Standard errors are clustered at the regional level and are displayed in parentheses ${ }^{a} \%$ significance, ${ }^{b}$ indicates $10 \%$ significance and ${ }^{\mathrm{c}} 1 \%$ significance

\subsection{Results by age groups}

We explore if results differ by age. In particular, one may suspect that the overall results would largely be driven by young individuals, given their weaker attachment to the labor market. Differential effects by age were documented by Hoynes et al. (2012), whereas Clark and Summers (1981) found no such evidence in the age span of 20-64. None of these studies considered combinations of age and skill.

Apart from their stronger labor market attachment, there is also another reason why results might be less pronounced for older individuals: Our measures of health, cognitive ability and non-cognitive ability are determined at the age 18, and these may be expected to be better indicators of current health, cognitive ability and noncognitive ability in young adulthood than at older ages. This may mostly be a concern for health and not so much for cognitive and non-cognitive abilities because studies have shown that the latter are relatively constant through adulthood (e.g., Cunha et al. 2006).

In Table 11, we run our main analysis on three non-overlapping age groups: individuals between 20 and 30 years of age, individuals between 31 and 41 and individuals aged 42 or older. Since results are relatively imprecise, we also show them without region-fixed effects and region interactions. However, estimates from models without region effects are often larger than their counterparts based on models including region effects, and it is possible that they are biased upwards. In particular, among the 15 instances where the estimate is significant according to at least one of the two models, the estimate is more negative according to the model without region effects in 12 cases. 
Table 10 Accounting for occupations

\begin{tabular}{|c|c|c|c|c|}
\hline & (A) & (B) & (C) & (D) \\
\hline \multicolumn{5}{|l|}{ UR interacted with: } \\
\hline \multirow[t]{2}{*}{ Intermediate health } & -0.067 & & & -0.004 \\
\hline & $(0.042)$ & & & $(0.041)$ \\
\hline \multirow[t]{2}{*}{ Poor health } & $-0.286^{\mathrm{a}}$ & & & -0.183 \\
\hline & $(0.101)$ & & & $(0.121)$ \\
\hline \multirow[t]{2}{*}{ Medium cognitive ability } & & $-0.163^{b}$ & & $-0.152^{c}$ \\
\hline & & $(0.079)$ & & $(0.082)$ \\
\hline \multirow[t]{2}{*}{ Low cognitive ability } & & $-0.275^{b}$ & & $-0.249^{b}$ \\
\hline & & $(0.108)$ & & $(0.117)$ \\
\hline \multirow[t]{2}{*}{ Medium non-cog. ability } & & $-0.170^{\mathrm{b}}$ & & $-0.157^{b}$ \\
\hline & & $(0.074)$ & & $(0.076)$ \\
\hline \multirow[t]{2}{*}{ Low non-cog. ability } & & $-0.510^{\mathrm{a}}$ & & $-0.448^{\mathrm{a}}$ \\
\hline & & $(0.161)$ & & $(0.152)$ \\
\hline \multirow[t]{2}{*}{ Secondary education } & & & $-0.294^{b}$ & -0.023 \\
\hline & & & $(0.103)$ & $(0.084)$ \\
\hline \multirow[t]{2}{*}{ Primary education } & & & $-0.305^{\mathrm{b}}$ & -0.031 \\
\hline & & & $(0.140)$ & $(0.148)$ \\
\hline Observations & & & $5,137,438$ & \\
\hline
\end{tabular}

Standard errors are clustered at the regional level and are displayed in parentheses

${ }^{a} 1 \%$ significance, ${ }^{b} 5 \%$ significance and ${ }^{c}$ indicates $10 \%$ significance

Without region effects, the main effect of unemployment is significant only among young individuals, but including these effects the pattern reverses and it is only among the older that the main effect is found to be significant.

Regarding the interactions with health and skills, we find the following results. First, there is evidence of higher unemployment sensitivity for individuals in poor health among both young and older individuals. But we do not obtain statistical significance for any age group when region effects are accounted for. There is also some evidence of a higher sensitivity to the unemployment rate among older individuals in intermediate health when not accounting for region effects.

Second, there is evidence of differential effects by cognitive ability in both the younger and middle-aged age group. This holds when accounting for region effects, but for the middle-aged, the coefficient has the unexpected sign. Third, individuals with a medium or with a low non-cognitive ability have larger unemployment sensitivity in all of the age groups in most specifications. Effects are not very dissimilar for the different age groups, and applying a $t$-test they are only statistically different in one case: when comparing the effect of having a medium non-cognitive ability among those aged 20-30 to the one among those aged 42 and older and accounting for region effects.

Fourth and finally, we find a large sensitivity among individuals with primary education in the group of young workers, but only when not accounting for region effects. For the oldest group, there is some evidence of a lower sensitivity. In sum, our results by age groups show several strong effects and they suggest that differential sensitivity to unemployment by health or non-cognitive skill group is not limited to individuals of a certain age. 
Table 11 Results by age groups

\begin{tabular}{|c|c|c|c|c|c|c|}
\hline \multirow{2}{*}{ Unemployment rate } & \multicolumn{2}{|c|}{ 20-30 years } & \multicolumn{2}{|c|}{$31-41$ years } & \multicolumn{2}{|c|}{42 years or older } \\
\hline & -0.057 & $-0.519^{a}$ & -0.147 & 0.039 & $-0.262^{\mathrm{a}}$ & 0.204 \\
\hline & $(0.296)$ & $(0.202)$ & $(0.203)$ & $(0.165)$ & $(0.122)$ & $(0.190)$ \\
\hline \multicolumn{7}{|l|}{ UR interacted with: } \\
\hline \multirow[t]{2}{*}{ Intermediate health } & -0.020 & -0.012 & -0.082 & -0.064 & -0.038 & $-0.091^{b}$ \\
\hline & $(0.127)$ & $(0.050)$ & $(0.102)$ & $(0.088)$ & $(0.094)$ & $(0.049)$ \\
\hline \multirow[t]{2}{*}{ Poor health } & -0.367 & $-0.411^{c}$ & -0.364 & -0.136 & -0.075 & $-0.432^{a}$ \\
\hline & $(0.250)$ & $(0.109)$ & $(0.277)$ & $(0.278)$ & $(0.211)$ & $(0.203)$ \\
\hline \multirow[t]{2}{*}{ Medium cog. ability } & -0.060 & 0.005 & 0.075 & 0.040 & 0.026 & 0.069 \\
\hline & $(0.183)$ & $(0.065)$ & $(0.105)$ & $(0.045)$ & $(0.108)$ & $(0.068)$ \\
\hline \multirow[t]{2}{*}{ Low cognitive ability } & $-0.468^{b}$ & 0.015 & $0.280^{b}$ & 0.026 & -0.025 & -0.027 \\
\hline & $(0.262)$ & $(0.141)$ & $(0.145)$ & $(0.093)$ & $(0.130)$ & $(0.168)$ \\
\hline \multirow[t]{2}{*}{ Medium non-cog. ability } & $-0.344^{a}$ & $-0.146^{b}$ & -0.197 & $-0.231^{a}$ & 0.101 & $-0.206^{\mathrm{C}}$ \\
\hline & $(0.169)$ & $(0.083)$ & $(0.129)$ & $(0.099)$ & $(0.107)$ & $(0.060)$ \\
\hline \multirow[t]{2}{*}{ Low non-cog. ability } & -0.326 & $-0.557^{a}$ & $-0.488^{c}$ & $-0.710^{c}$ & -0.203 & $-0.465^{\complement}$ \\
\hline & $(0.362)$ & $(0.220)$ & $(0.180)$ & $(0.170)$ & $(0.170)$ & $(0.096)$ \\
\hline \multirow[t]{2}{*}{ Secondary education } & 0.232 & 0.353 & 0.077 & 0.249 & 0.012 & -0.076 \\
\hline & $(0.201)$ & $(0.244)$ & $(0.146)$ & $(0.208)$ & $(0.097)$ & $(0.185)$ \\
\hline \multirow[t]{2}{*}{ Primary education } & 0.381 & $-0.457^{\mathrm{a}}$ & -0.000 & -0.077 & $0.238^{b}$ & -0.169 \\
\hline & $(0.338)$ & $(0.198)$ & $(0.242)$ & $(0.449)$ & $(0.142)$ & $(0.534)$ \\
\hline Region effects & $x$ & & $x$ & & $x$ & \\
\hline Observations & \multicolumn{2}{|c|}{$1,277,286$} & \multicolumn{2}{|c|}{$2,141,487$} & \multicolumn{2}{|c|}{$2,114,620$} \\
\hline
\end{tabular}

Standard errors are clustered at the regional level and are displayed in parentheses

${ }^{a} 5 \%$ significance, ${ }^{b}$ indicates $10 \%$ significance and ${ }^{\mathrm{c}} 1 \%$ significance

\section{6 "More exogenous" unemployment rates}

The local unemployment rate may stem from general supply and demand factors that are not affected by the individuals we study. It could also be the other way around however: Variation in local unemployment rates may be determined by men who belong to the cohorts we study and possess characteristics such as poor health or low non-cognitive skills. If this is the case, our results do not reflect heterogeneous responses to general supply and demand, but instead variations related to the supply and demand of certain groups of workers. We here try to deal with this by running the analysis using unemployment rates that are not based on individuals included in the sample but yet are correlated with the unemployment rates that these people are exposed to.

First, in Table 12, we use the youth unemployment rate (unemployment in the group of individuals aged 18-24) and restrict the sample to those aged 25 or older. We find that this does not eliminate our results. The response of individuals in poor health does become insignificant in the full model, but there is still evidence that individuals with a low non-cognitive ability have worse outcomes when unemployment is higher. There is also evidence that this is the case for those with a low cognitive ability.

Second, in Table 13, we use the female unemployment rate rather than the overall one. Again, the results for non-cognitive ability are not eliminated, although poor health is again not statistically significant in the full model. While factors specifically affecting men (or those aged 25 or more) with a low non-cognitive ability may of course also be related to factors affecting women (or youths), our findings provide an 
Table 12 Employment explained by youth unemployment

\begin{tabular}{|c|c|c|c|c|c|}
\hline & (A) & (B) & (C) & (D) & (E) \\
\hline \multirow[t]{2}{*}{ Unemployment rate } & -0.061 & -0.030 & 0.025 & -0.014 & 0.035 \\
\hline & $(0.037)$ & $(0.036)$ & $(0.056)$ & $(0.060)$ & $(0.069)$ \\
\hline \multicolumn{6}{|l|}{ UR interacted with: } \\
\hline \multirow[t]{2}{*}{ Intermediate health } & & -0.037 & & & -0.017 \\
\hline & & $(0.025)$ & & & $(0.026)$ \\
\hline \multirow[t]{2}{*}{ Poor health } & & $-0.093^{\mathrm{a}}$ & & & -0.015 \\
\hline & & $(0.049)$ & & & $(0.054)$ \\
\hline \multirow[t]{2}{*}{ Medium cognitive ability } & & & -0.012 & & -0.009 \\
\hline & & & $(0.041)$ & & $(0.038)$ \\
\hline \multirow[t]{2}{*}{ Low cognitive ability } & & & -0.084 & & $-0.080^{\mathrm{a}}$ \\
\hline & & & $(0.053)$ & & $(0.046)$ \\
\hline \multirow[t]{2}{*}{ Medium non-cog. ability } & & & -0.030 & & -0.027 \\
\hline & & & $(0.035)$ & & $(0.034)$ \\
\hline \multirow[t]{2}{*}{ Low non-cog. ability } & & & $-0.139^{b}$ & & $-0.133^{b}$ \\
\hline & & & $(0.063)$ & & $(0.063)$ \\
\hline \multirow[t]{2}{*}{ Secondary education } & & & & -0.053 & -0.014 \\
\hline & & & & $(0.060)$ & $(0.056)$ \\
\hline \multirow[t]{2}{*}{ Primary education } & & & & -0.090 & -0.005 \\
\hline & & & & $(0.065)$ & $(0.065)$ \\
\hline Observations & $5,274,855$ & & & & \\
\hline
\end{tabular}

Standard errors are clustered at the regional level and are displayed in parentheses aindicates $10 \%$ significance, ${ }^{b} 5 \%$ significance and ${ }^{\mathrm{c}} 1 \%$ significance

indication that individuals with lower non-cognitive ability and perhaps in worse health are, in fact, more affected by the general state of the labor market.

\section{Conclusion}

Using a comprehensive dataset of Swedish males, this study examined if the relationship between the local unemployment rate and individuals' labor market outcomes varies by predetermined characteristics such as health and abilities. Our findings consistently suggest that individuals in poor health or with a low non-cognitive ability are more affected by variations in the unemployment rate. Some models, such as the ones accounting for occupations, also indicated that lower educated and those with a low cognitive ability are more sensitive to the unemployment rate.

Our findings have implications for policy because they show that economic fluctuations have distributional consequences, as they impose risks on people with certain characteristics. Given our results, in poor economic times, policy makers may want to target their efforts particularly at individuals that are disadvantaged in terms of health or non-cognitive abilities. Moreover, the results provide another reason to invest in the health and skills of young individuals.

There are a few limitations of our study. First, we were only able to consider men. Since women have a weaker attachment to the labor market in general, their responses to the unemployment rate and its interactions with health and skills may be quite different from that of males. Second, the number of time periods in our data was small 
Table 13 Employment explained by female unemployment

\begin{tabular}{|c|c|c|c|c|c|}
\hline & (A) & (B) & (C) & (D) & (E) \\
\hline \multirow[t]{2}{*}{ Unemployment rate } & $-0.203^{\mathrm{a}}$ & -0.143 & -0.102 & -0.256 & -0.145 \\
\hline & $(0.112)$ & $(0.116)$ & $(0.183)$ & $(0.192)$ & $(0.219)$ \\
\hline \multicolumn{6}{|l|}{ UR interacted with: } \\
\hline \multirow[t]{2}{*}{ Intermediate health } & & $-0.096^{\mathrm{b}}$ & & & -0.055 \\
\hline & & $(0.040)$ & & & $(0.039)$ \\
\hline \multirow[t]{2}{*}{ Poor health } & & $-0.215^{c}$ & & & -0.164 \\
\hline & & $(0.074)$ & & & $(0.109)$ \\
\hline \multirow[t]{2}{*}{ Medium cognitive ability } & & & 0.013 & & -0.014 \\
\hline & & & $(0.085)$ & & $(0.066)$ \\
\hline \multirow[t]{2}{*}{ Low cognitive ability } & & & 0.007 & & 0.000 \\
\hline & & & $(0.133)$ & & $(0.114)$ \\
\hline \multirow[t]{2}{*}{ Medium non-cog. ability } & & & $-0.090^{\mathrm{a}}$ & & -0.079 \\
\hline & & & $(0.050)$ & & $(0.050)$ \\
\hline \multirow[t]{2}{*}{ Low non-cog. ability } & & & $-0.371^{c}$ & & $-0.315^{c}$ \\
\hline & & & $(0.115)$ & & $(0.102)$ \\
\hline \multirow[t]{2}{*}{ Secondary education } & & & & 0.015 & 0.057 \\
\hline & & & & $(0.116)$ & $(0.101)$ \\
\hline \multirow[t]{2}{*}{ Primary education } & & & & -0.086 & 0.028 \\
\hline & & & & $(0.112)$ & $(0.103)$ \\
\hline Observations & & & $5,533,393$ & & \\
\hline
\end{tabular}

Standard errors are clustered at the regional level and are displayed in parentheses aindicates $10 \%$ significance, ${ }^{b} 5 \%$ significance and ${ }^{c} 1 \%$ significance

(only five), and we were not able to include years of large business cycle swings. Studies using more observations over time would be able to exploit larger variations in unemployment rates, and they could look into the effects of more specific aspects of health and abilities, as well as long-term effects.

\section{Endnotes}

${ }^{1}$ Notable work on welfare losses due to business cycles includes Lucas (1987), Krusell and Smith (1999) and Galí et al. (2007).

${ }^{2}$ In a more descriptive exercise, Edin et al. (2000) documented that lower-skilled youths in Sweden experienced a larger increase in unemployment than did higherskilled youths around the time of the recession during the early $90 \mathrm{~s}$.

${ }^{3}$ Another literature related to ours has shown that immigrants are more sensitive to local unemployment and has pointed to the importance of favorable labor market conditions for assimilation (e.g., Barth et al. 2004; Bratsberg et al. 2006, 2010; Åslund and Rooth 2007).

${ }^{4}$ They also used the same registers in, for example, Lundborg et al. (2014b).

${ }^{5}$ Early in data period, males were typically called to undergo the military enlistment procedure the year they turned 19, whereas in later years it most often took place the year the individual turned 18.

${ }^{6}$ Any health problem, present or historic, that may interfere with the individual's ability to undergo military service is supposed to be reflected in our measure of overall health status. The individual had to bring any doctor's certificate, health record, drug 
prescription, or similar to the NSA proving that he actually suffered from the conditions he reported in his health declaration.

${ }^{7}$ We do not have information on when (or if) specific individuals actually underwent military education. However, we can observe if individuals were employed by the military after finishing their military education. These individuals comprise less than $1 \%$ of the population, and our results are not sensitive to their exclusion.

${ }^{8}$ Government benefits (such as unemployment benefits, sick leave benefits, or benefits obtained in association with military education) are not included.

${ }^{9}$ We cannot observe whether individuals are currently enrolled in education. Individuals undergoing education are less likely to work and may therefore be less affected by the unemployment rate. On the other hand, their weaker attachment to the labor market may also make them more sensitive to the unemployment rate. We have tried dropping individuals with a different level of final education in the year of observation and in 2007, and this made little difference for our results.

${ }^{10}$ Indeed, laid-off individuals that are able to quickly find new employment are classified as employed according to our definition. These individuals may be laid-off due to low productivity but are able to find new employment by hiding their low productivity from prospective employers. For example, unless the recruitment involves an IQ test, a low cognitive ability may be possible to hide, and as a result individuals with a low cognitive ability may only experience rather short unemployment spells. In line with this, Lindqvist and Vestman (2011) documented that non-cognitive, but not cognitive ability, predicted the duration of unemployment spells.

${ }^{11}$ In $1.3 \%$ of cases, we are unable to assign a local unemployment rate to an individual, either because we do not observe a place of residence or because there is no information on local unemployment available.

${ }^{12} \mathrm{We}$ improve on their specifications, however, by adding interactions between all years, $Y$, and indicators for health and skills, and also interactions between all regions, $R$, and indicators for health and skills.

${ }^{13}$ The equations do not include the main effect of $A$ since this would be perfectly multicollinear with the set of interactions between $A$ and $Y$ (or with the set of interactions between $A$ and $R$ ).

${ }^{14}$ The disadvantage of using region effects and their interactions is that precision may become smaller, since our regressions in effect compare outcomes within regions, where only five time points are observed. We therefore also run regressions where regions are not accounted for.

${ }^{15}$ Bennmarker et al. (2007) documented that the median unemployment spell in Sweden is about 13 weeks. Spells may, however, not only end because individuals find employment but also because they decide to leave the labor market.

${ }^{16}$ As noted, we have clustered standard errors at the regional level. Clustering at the individual level generates smaller standard errors and the main effects of unemployment then also become statistically significant.

${ }^{17}$ Another option is to depart from our main specification by adding region-specific linear trends. For example, the treatment of sickly individuals may vary over time within a region. The inclusion of these trends makes little difference for our results.

${ }^{18}$ SEK 100,000 corresponds to about USD 10,100 if converting using the OECD exchange rate for private consumption. Antelius and Björklund (2000) have shown that 
if one uses a threshold of SEK 100,000 when estimating the return to schooling based on Swedish tax records, one obtains a result that closely resembles the one obtained when analyzing real wages per hour. Thus, by not counting individuals with an income of less than SEK 100,000 as employed we are likely to exclude many individuals that work less than full time throughout a year.

${ }^{19}$ Since we need information on the region of residence 2 years ahead in time when running these regressions, we have to exclude observations from 2007.

${ }^{20} \mathrm{On}$ the other hand, the disadvantage of not accounting for region effects is that mobility patterns may differ between regions in a way that is just correlated with unemployment. Mobility may also respond to unemployment with a lead or a lag of several years, but this is less of a problem when employing our main identification strategy since we consider contemporaneous effects of unemployment variations.

${ }^{21}$ Specifically, our data includes occupational identifiers obtained from Statistics Sweden in 2003, 2005, and 2007. These data are not always updated yearly, however, so they should not be seen as referring to specific year. We use data on occupation from 2003 when this is available, otherwise we use data from 2005, and if this is also not available we use data from 2007. For about $8 \%$ of all individuals there is no data on occupation available for any of these years. Rather than dropping these individuals, we treat them as belonging to one and the same occupational category.

${ }^{22}$ For computational reasons, we do not include interactions between occupation and region effects.

${ }^{23}$ Note that this table does not include the main effect of the unemployment rate since this would depend on the arbitrary choice of what (interaction between the unemployment rate and) occupational category is excluded.

Competing interests

IZA Journal of Labor Policy is committed to the IZA Guiding Principles of Research Integrity. The author declares that he has observed these principles and that he has no competing interests.

\section{Acknowledgements}

The author thanks Petter Lundborg, Dan-Olof Rooth, Hans Grönqvist, Martin Salm and an anonymous referee for useful comments and suggestions and Ingvar Ahlstrand and Björn Bäckstrand at the National Service Administration for providing information on the military enlistment procedure. The author also thanks Michael John Howard for proofreading the manuscript. Research grants from The Jan Wallander and Tom Hedelius Foundation and from The Crafoord Foundation are gratefully acknowledged.

Responsible editor: Juan F Jimeno

Received: 14 November 2014 Accepted: 15 July 2015

Published online: 13 October 2015

References

Almond D, Currie J (2011) Human capital development before age five. In: Ashenfelter O, Card D (eds) Handbook of Labor Economics, Vol 4b. North Holland, Amsterdam, pp 1315-1486

Antelius J, Björklund A (2000) How reliable are register data for studies of the return on schooling? An examination of Swedish data. Scand J Educ Res 44:341-355

Åslund O, Rooth D-O (2007) Do when and where matter? Initial labor market conditions and immigrant earnings. Econ J 117:422-448

Barth E, Bratsberg B, Raaum O (2004) Identifying earnings assimilation of immigrants under changing macroeconomic conditions. Scand J Econ 106(1):1-22

Bartik TJ (1996) The distributional effects of local labor demand and industrial mix: estimates using individual panel data. J Urban Econ 40:150-178

Bennmarker H, Carling K, Holmlund B (2007) Do benefit hikes damage job finding? Evidence from Swedish unemployment insurance reforms. Labour 21:85-120

Biddle J, Hamermesh DS (2013) Wage discrimination over the business cycle. IZA Journal of Labor Policy 2:1-19

Bound J, Holzer H (1995) Structural changes, employment outcomes and population adjustments among whites and blacks: 1980-1990. Institute for Research on Poverty Paper 1057-1095

Bratsberg B, Barth E, Raaum O (2006) Local unemployment and the relative wages of immigrants: evidence from the current population surveys. Rev Econ Stat 88:243-263 
Bratsberg B, Raaum O, Røed K (2010) When minority labor migrants meet the welfare state. J Labor Econ 28:633-676 Card D (1999) The causal effect of education on earnings. In: Ashenfelter O, Card D (eds) Handbook of Labor Economics, Vol 3a. North Holland, Amsterdam, pp 1801-1863

Carneiro A, Portugal P (2006) Earnings losses of displaced workers: Evidence from a matched employer-employee data set. IZA Discussion Paper 2289

Cebi M (2007) Locus of control and human capital investment revisited. J Hum Resour 42:919-932

Charles KK (2003) The longitudinal structure of earnings losses among work-limited disabled workers. J Hum Resour 38:618-646

Clark KB, Summers LH (1981) Demographic differences in cyclical employment variation. J Hum Resour 16:61-79

Couch KA, Placzek DW (2010) Earnings losses of displaced workers revisited. Am Econ Rev 100:572-589

Couch KA, Jolly NA, Placzek DW (2009) Earnings losses of older displaced workers: a detailed analysis with administrative data. Res Aging 31:17-40

Couch KA, Jolly NA, Placzek DW (2011) Earnings losses of displaced workers and the business cycle: an analysis using administrative data. Econ Lett 111:16-19

Cunha F, Heckman JJ, Lochner L (2006) Interpreting the evidence on life-cycle skill formation. In: Hanushek EA, Welch F (eds) Handbook of the Economics of Education, vol 1. North Holland, Amsterdam, pp 697-812

Currie J, Tekin E (2011) Is the foreclosure crisis making us sick? NBER Working Paper 17310

Currie J, Stabile M, Manivong P, Roos LL (2010) Child health and young adult outcomes. J Hum Resour 45:517-548

Da Vanzo J (1983) Repeat migration in the United States: Who moves back and who moves on? Rev Econ Stat 65:552-559

Edin P-E, Forslund A, Holmlund B (2000) The Swedish youth labor market in boom and depression. In: Blanchflower DG, Freeman RB (eds) Youth Unemployment and Joblessness in Advanced Countries. University of Chicago Press, Chicago, pp 357-380

Eliasson K, Westerlund O (2009) Geographical mobility in Sweden - does the influence of labour-market related factors diminish over time? Department of Economics, Umeå University, Mimeo

Eriksson S, Rooth D-O (2014) Do employers use unemployment as a sorting criterion when hiring? Evidence from a field experiment. Am Econ Rev 104:1014-1039

Farber HS (1993) The incidence and costs of job loss in the United States, 1981-1995. Brookings Papers on Economic Activity. Microeconomics 1

Farber HS (2003) Job Loss in the United States, 1981-2001. NBER Working Paper 9707

Försvarsmakten (1980) Handbok för medicinpersonal inom Försvarsmakten. Uddevalla

Galí J, Gertler M, López-Salido D (2007) Markups, gaps and the welfare costs of business fluctuations. Rev Econ Stat 89:44-59

Heckman JJ, Borjas GJ (1980) Does unemployment cause future unemployment? Definitions, questions and answers from a continuous time model of heterogeneity and state dependence. Economica 47:247-283

Heckman JJ, Stixrud J, Urzua S (2006) The effects of cognitive and noncogntive abilities on labor market outcomes and social behavior. J Labor Econ 24:411-482

Heineck G, Anger S (2010) The returns to cognitive abilities and personality traits in Germany. Labour Econ 17:535-546

Hines JR Jr, Hoynes H, Krueger AB (2001) Another look at whether a rising tide lifts all boats. In: Krueger AB, Solow R (eds) The Roaring Nineties: Can Full Employment be Sustained? Russell Sage, New York, pp 493-537

Holmlund B (1984) Labor Mobility: Studies of Labor Turnover and Migration in the Swedish Labor Market. Industriens Utredningsinstitut, Stockholm

Hoynes H (2000) The employment, earnings and income of less skilled workers over the business cycle. In: Card DE, Blank RM (eds) Finding Jobs: Work and Welfare Reform. Russell Sage, New York

Hoynes H, Miller DL, Schaller J (2012) Who suffers during recessions? J Econ Perspect 26:27-48

Jacobson LS, LaLonde L, Sullivan DG (1993) Earnings losses of displaced workers. Am Econ Rev 83:685-709

Kletzer LG (1998) Job displacement. J Econ Perspect 12:115-136

Krusell P, Smith AA (1999) On the welfare effects of eliminating business cycles. Rev Econ Dynam 2:245-272

Lindqvist $E$, Vestman $R$ (2011) The labor market returns to cognitive and noncognitive ability: evidence from the Swedish enlistment. Am Econ J App 3:101-128

Lucas RE Jr (1987) Models of Business Cycles. Basil Blackwell, New York

Lundborg P, Nilsson M, Vikström J (2011) Socioeconomic heterogeneity in the effect of health shocks on earnings: Evidence from population-wide data on Swedish workers. IZA Discussion Paper 6121

Lundborg P, Nilsson A, Rooth D-O (2014a) Adolescent health and adult labor market outcomes. J Health Econ 37:25-40

Lundborg P, Nilsson A, Rooth D-O (2014b) Parental education and offspring outcomes: evidence from the Swedish compulsory school reform. Am Econ J App 6:2543-2578

Madden JF (1988) The distribution of economic losses among displaced workers: measurement methods matter J Hum Resour 23:93-107

Nicoletti G, Scarpetta S, Boylaud O (1999) Summary indicators of product market regulation with an extension to employment protection legislation. OECD Economics Department Working Papers 226

Pissarides A, Wadsworth J (1989) Unemployment and the Inter-Regional Mobility of Labour. Econ J 99:739-755

Raaum O, Røed K (2006) Do business cycle conditions at the time of labor market entry affect future employment prospects? Rev Econ Stat 88:193-210

Rabe B, Taylor M (2012) Differences in opportunities? Wage, employment and house-price effects on migration. Oxford B Econ Stat 74:831-855

Ruhm CJ (2000) Are recessions good for your health? Q J Econ 115:617-650

Seitchik A (1991) Who are displaced workers? In: Addison JT (ed) Job Displacement: Consequences and Implications for Policy, Wayne State University Press, Detroit, pp 51-82

Smith JP (1999) Healthy bodies and thick wallets: the dual relationship between health and economic status. J Econ Perspect 13:145-166 
Stevens AH (1997) Persistent effects of job displacement: the importance of multiple job losses J Labor Econ 15:165-188

Stillman S, Thomas D (2008) Nutritional status during an economic crisis: evidence from Russia. Econ J 118:1385-1417

Sullivan D, von Wachter T (2009) Job displacement and mortality: an analysis using administrative data. Q J Econ 124:1265-1306

Tobin J (1972) Inflation and unemployment. A Econ Rev 62:1-18

Westerlund O (1997) Employment opportunities, Wages and interregional migration in Sweden 1970-1989. J Regional Sci 37:55-73

Westerlund O, Wyzan ML (1995) Household migration and the local public sector: evidence from Sweden 1981-1984. Reg Stud 29:145-157

Submit your manuscript to a SpringerOpen ${ }^{\circ}$ journal and benefit from:

- Convenient online submission

- Rigorous peer review

- Immediate publication on acceptance

- Open access: articles freely available online

- High visibility within the field

- Retaining the copyright to your article

Submit your next manuscript at $\boldsymbol{\nabla}$ springeropen.com 